\title{
Motivational Attitudes and Behaviors in Capstone Projects: Quantitative Validation of Assessment Instruments
}

\section{Bashirah Ibrahim, Ohio State University}

Bashirah Ibrahim is a postdoctoral researcher in engineering education at the Ohio State University.

\section{Dr. Peter Rogers, Ohio State University}

Dr. Peter Rogers is a Professor of Practice in the Department of Engineering Education The Ohio State University. He joined the university in October 2008 bringing with him 35 years of industrial experience. His career includes senior leadership roles in engineering, sales, and manufacturing developing products using multidisciplinary teams to convert customer needs to commercially viable products and services. Rogers co-led the development of an ABET-approved year-long Capstone design experience. With a focus on providing students with a broader experience base, the multidisciplinary program applies teams of engineers, business, design, and other students to work with companies to help them be more competitive. Rogers expanded this one-year program to a four-year Integrated Business and Engineering (IBE) honors program.

Rogers earned his Ph.D. at the University of Massachusetts, Amherst, focused on mechanical engineering and manufacturing

\section{Dr. Denny C. Davis, Ohio State University}

Dr. Davis is Visiting Professor in the Engineering Education Department at The Ohio State University and Emeritus Professor in Engineering Education at Washington State University. For three decades, he has led multi-institution teams in the development and testing of curriculum materials and assessments for engineering design courses. He is the owner of Verity Design Learning LLC, a publisher of workbooks for design reviews and teamwork development. He is a Fellow of the American Society for Engineering Education.

\section{Lin Ding, Ohio State University}

Lin Ding, Ph.D., is an associate professor in the Department of Teaching and Learning at The Ohio State University. Dr. Ding's scholarly interests lie in discipline-based STEM education research. His work includes theoretical and empirical investigations of student content learning, problem solving, reasoning skills, and epistemological development. Dr. Ding specializes in research-based assessment development and focuses primarily on the quantitative research paradigm. He has published numerous high-impact journal articles, book chapters, and research proceedings papers. In addition, Dr. Ding has been leading multiple federal and state projects sponsored by the National Science Foundation (NSF) and the Ohio Department of Education. Also, he frequently serves as an invited editorial board member, referee or panelist for various international journals, funding agencies, and professional associations.

\section{Kaycee Ash, Ohio State University}

Kaycee Ash is a Chemical Engineering undergraduate student at The Ohio State University. She started working towards her Bachelor's of Science degree in August 2014. In the past, she has worked with other students by helping them better themselves academically, and she has worked on chemical manufacturing and transport at Ohio Chemical Services. She joined the research team in December of 2015 and is currently working on assessing motivation in academia. 


\title{
Motivational Attitudes and Behaviors in Capstone Projects: Quantitative Validation of Assessment Instruments
}

\begin{abstract}
This research paper reports the quantitative validation of instruments for assessing engineering students' motivational attitudes and behaviors in their capstone design course. Motivation plays a key role in engineering practice, particularly with respect to students' efficiency and effectiveness as well as their readiness to engage in teamwork either in the capstone course or the workplace. The 2013 ASEE report on Transforming Undergraduate Education of Engineers has identified fifteen personal and professional abilities to be developed in engineering graduates, one of which is motivation. Prior research by the authors confirmed and prioritized the need for professional skills which should be developed in capstone design courses-those which are usually not effectively developed in engineering graduates. Assessing students' motivation in engineering programs provides a foundation for future curriculum improvement.
\end{abstract}

We designed and implemented several assessment instruments over a two-year period. This paper focuses on the two latest instruments for assessing students' motivational attitudes and behaviors. One of the Likert scale instruments consists of 20 intrinsic and extrinsic motivational attitudes. The other includes 20 motivational behaviors grouped into five categories: work quality and quantity, level of supervision, team effectiveness, initiative, and self-development. The behaviors instrument also includes a peer evaluation of the above-mentioned five categories of behaviors.

The instruments were administered via Qualtrics. The attitudes instrument was completed by 303 students during the first few weeks of their capstone course. The behaviors instrument was completed by the same group of students, a total of 204 participants, mid-way in their capstone course. The participants were from six institutions, ranging from large public universities to small private colleges including an all-female institution. The participants spent an average of 10 minutes to complete the instrument. We calculated the reliability index of the instruments for the extent to which the measurements are repeatable, and the item discrimination index for the extent to which the items can distinguish highly motivated students from poorly motivated ones. Statistical validation of the attitudes instrument yielded a reliability index of 0.71 (desired range: $\geq 0.7$ ) and item discrimination index $\geq 0.3$ (the ideal range) for 14 of the 20 items. For the behaviors instrument, the reliability index is 0.74 and the item discrimination index is $\geq 0.3$ for only 5 of the 20 items. The results indicate that these instruments are moderately reliable for group measurement. Further, most of the motivational attitudes items allow us to distinguish between students who are highly and weakly motivated as opposed to the motivational behaviors items. The research team subsequently made small modifications to those items with the lowest discrimination scores to make them more specific to capstone courses; the team will re-validate them after the second application of this instrument. Successful attainment of reliable and valid instruments provides the foundation for potential curriculum changes in the design and teaching of capstone courses to improve motivational growth and better prepare students for careers. 


\section{Introduction}

For decades, the engineering profession has expressed concerns that US universities are not preparing engineering graduates adequately to keep the nation competitive [1]. A recent national workshop [2] of engineering employers identified 36 basic knowledge, skills, and abilities (KSAs) that are important in engineers entering the workforce. Among these, $15 \mathrm{KSAs}$ were identified as most important and yet under-developed in graduates - one of which is self-drive and motivation. A subsequent workshop [3] of engineering students revealed perceptions of a similar lack of preparation and attention given by institutions to develop self-drive and motivation in engineering students. Although students and employers recognize the educational deficiency in developing student's self-drive and motivation, few institutions address this need specifically.

In engineering curricula, development of professional skills occurs often in project-based learning experiences and extracurricular activities [2]. At most institutions, required experiences with intentional professional skills learning are found predominantly in first-year or senior design projects. If specific skills are not assessed, they are not taken seriously, students do not receive useful feedback, learning activities are not properly focused, and outcomes are not developed consistently in students [4]. In engineering programs, self-drive and motivation is rarely mentioned as a desired outcome nor assessed and therefore is not developed consistently in all students.

Students benefit from both formative and summative assessment. Formative assessment, providing feedback to guide improvement, enables students to adjust their learning based on understanding of their strengths and weaknesses. Summative assessment, measuring achievement, enables students to know how they have advanced in learning and how their achievements compare to expectations [5]. High quality assessment must have clear purpose, clear targets, methods that match the targets and purpose, sound sampling, and absence of bias [6].

Valid assessment of self-drive and motivation requires observation or data gathering in the context in which motivation is being developed and applied. Because all engineering programs require capstone or similar design project experiences, the capstone design project course was selected as a natural site for assessment of self-drive and motivation. Existing instruments for assessing motivation typically are not developed for or tested within the context of capstone design courses $[7,8,9,10]$. Thus, the research team has developed assessments specifically for student motivation in capstone design project courses.

Assessment of self-drive and motivation, primarily an affective outcome, requires methods that probe students' perceptions and visible evidence of being motivated. This led the authors to focus separate assessment instruments on attitudes aligned with project-related motivation and behaviors that give evidence of self-drive [11]. Attitudes were identified from early studies of what students identified as motivators for them. Attitudes are characterized as extrinsic or intrinsic, respectively, depending upon whether the student benefits from tangible external rewards or primarily from internal feelings. Behaviors were derived from the authors' long experience of teaching capstone project courses and observing or receiving feedback from teammates on member motivations. Five categories of behaviors arose from grouping a list of 
behaviors that the authors identified with motivated students: quality and quantity of their work, taking initiative, support given to one's team, need for supervision, and engaging in selfdevelopment.

In this paper we report the quantitative validation of two instruments, Motivational Attitudes and Motivational Behaviors designed earlier [11]. In this paper, we address the following research question: To what extent are the motivational attitudes and behaviors instruments reliable for documenting students' motivations in their capstone course?

\section{Method}

During the Spring of 2017, an initial version of the motivational attitudes and behaviors instruments were completed by 124 students enrolled in a capstone course at a large public Midwestern university. During the Fall of 2017, an updated version of both instruments was administered to capstone students from six institutions, ranging from large public universities to small private colleges including an all-female college. The motivational attitudes instrument was completed by 303 students during the first weeks of their capstone course, typically by the first week of September. The motivational behaviors instrument was administered to the same group of students (a total of 204 participants), mid-way in their capstone course, normally by the end of November or early December. The reduction of the number of students indicates that some students who started the process opted not to continue.

\section{Motivational attitudes and behaviors instruments}

The initial version of the attitudes and behaviors Likert-scale instruments are shown in Table 1. They were designed after reviewing the literature for motivation constructs in capstone courses, several rounds of workshops with faculty from different institutions and from industry inputs. The design of the initial versions of these instruments is described in our earlier paper [11]. The attitudes instrument comprises 20 items. A total of ten items are categorized as extrinsic in nature (items 1, 2, 12, 14-20) and another ten items $(3-11,13)$ are classified as intrinsic.

Table 1: Initial version of attitudes instrument administered in Spring 2017

Attitudes Related to Motivation in a Project

1. I want this project to fulfill my capstone requirement for graduation

2. I want to receive good grades in my capstone project class

3. I want my project to develop me as a competent professional

4. I want my project to teach me how to apply technical knowledge to real problem

5. I want my project experience to enhance my abilities to work effectively in a team

6. I find the project experience interesting and enjoyable

7. I am passionate about my project

8. I want to fulfill my project-related team and client obligations

\begin{tabular}{|c|c|c|c|c|}
\hline 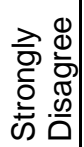 & 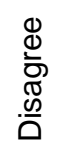 & 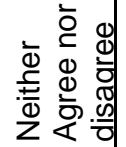 & ఖ & 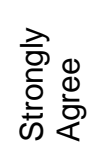 \\
\hline & & & & \\
\hline & & & & \\
\hline & & & & \\
\hline & & & & \\
\hline & & & & \\
\hline & & & & \\
\hline & & & & \\
\hline & & & & \\
\hline & & & & \\
\hline
\end{tabular}




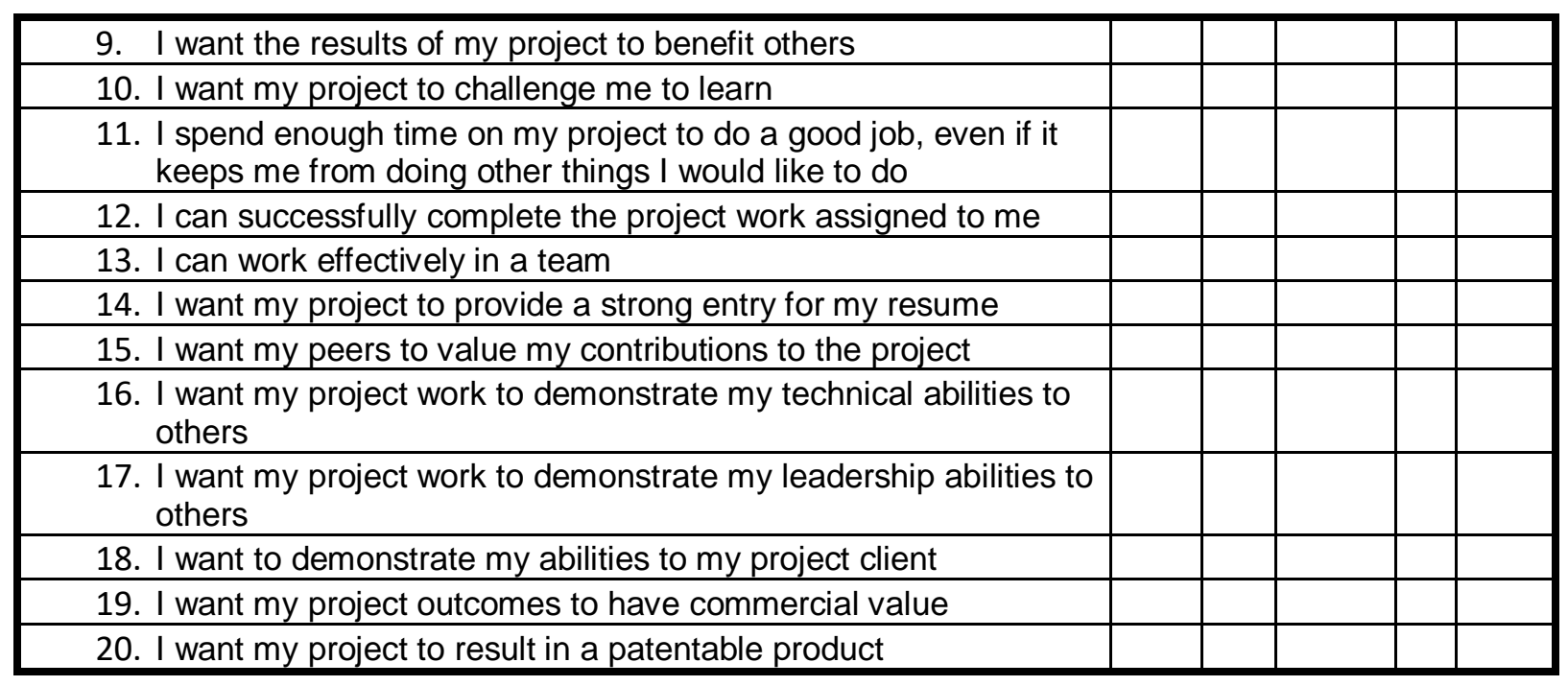

The behaviors instrument consists of 20 items for self-assessment. These items are grouped under the five elements comprising motivational behaviors: work quality and quantity $(1,7,8$, and 11), level of supervision $(5,9,16$, and 20), team effectiveness $(4,10,14$, and 19), initiative $(2,12,13$ and 18), and self-development (3, 6, 15 and 17). The instrument is shown in Table 2.

Table 2: Initial version of behavior instrument administered in Spring 2017

Behaviors in Design Projects

1. The amount of work I contribute to my project is generous and at least my fair share

2. It was challenging to initiate actions to start and complete work assigned to me

3. I do not work to improve my design project skills unless an obvious need arises

4. I perform work on our project with a mind toward enhancing my team's reputation

5. I monitor work quality to ensure that my outcomes meet my supervisor's standards

6. I have improved my interpersonal skills as needed in my project

7. I have needed extra time to complete my project work assignments

8. I feel that my contributions have provided limited value to the project

9. I communicate with others, including my supervisor, to keep everyone adequately informed to do our work well

10. I display attitudes that at times can discourage and demotivate my team

11. I focus my work effort on what is most important to the project

12. I quickly take action to confront and resolve problems

13. I am slow to take steps to identify and obtain resources needed for my project 


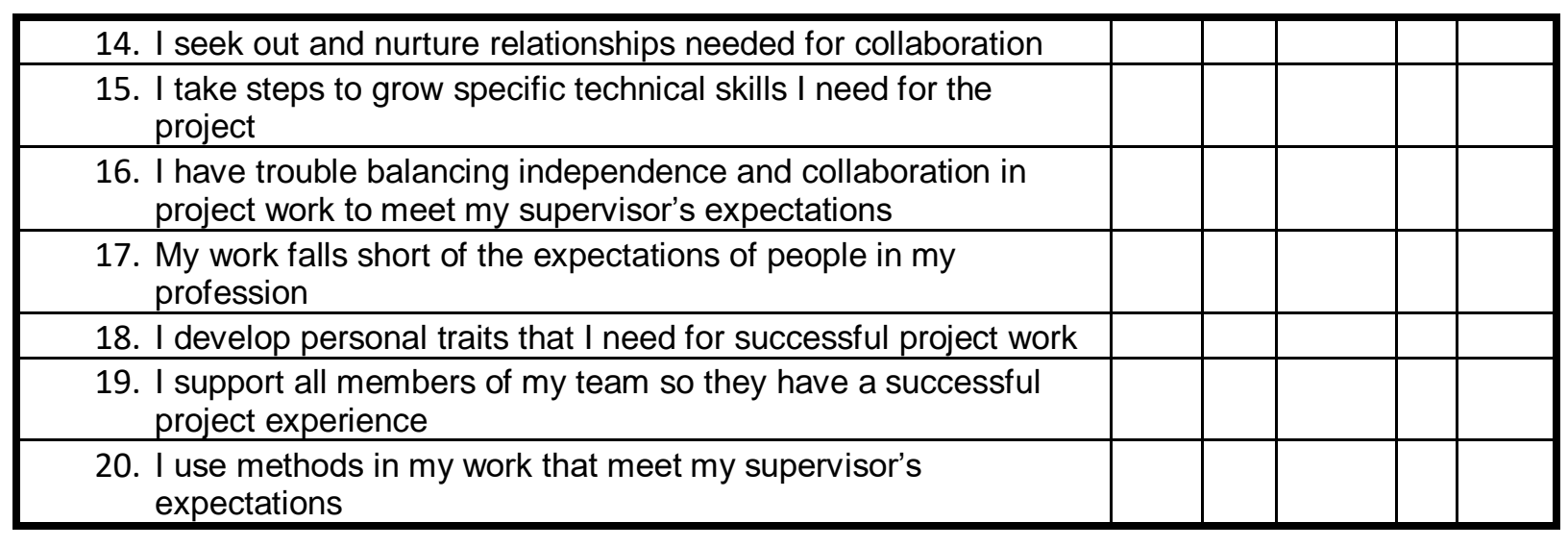

After completion of the initial versions of the instruments, focus groups were conducted with 12 capstone students and five faculty from a large public Midwestern university. The aim of the focus groups was to gather feedback on the structure, content, administration, and impact of the assessment tools. Table 3 and Table 4 summarize the discussed points and feedback during the faculty and student focus groups respectively.

Table 3: Feedback from faculty focus group

\begin{tabular}{|l|l|}
\hline Discussion Topic & Faculty Feedback \\
\hline $\begin{array}{l}\text { Assessment format - ways to make the } \\
\text { assessments user-friendly, preference to ask } \\
\text { students to rank-order, rate and describe issues } \\
\text { related to motivation or use a 5-point Likert scale. }\end{array}$ & $\begin{array}{l}\text { Prefer Likert-scale questions; Reword some } \\
\text { items; Make assessments automated, easy to } \\
\text { summarize, explain, implement and distribute. }\end{array}$ \\
\hline $\begin{array}{l}\text { Motivation aspects - relevance of the aspects of } \\
\text { motivations addressed in the assessments with } \\
\text { regards to the professional workplace and the } \\
\text { capstone course }\end{array}$ & $\begin{array}{l}\text { Points to consider: What tendencies will cause } \\
\text { you to struggle staying motivated? ; What } \\
\text { motivates you?; ;ow do you like to work? ; How } \\
\text { will you be motivated if you do not like the } \\
\text { project? }\end{array}$ \\
\hline $\begin{array}{l}\text { Number of outcomes - the potential barriers to } \\
\text { completing additional assessments in the capstone } \\
\text { class and how these barriers can be overcome }\end{array}$ & $\begin{array}{l}\text { Personalize the importance of the assessments; } \\
\text { Proper communication with more clear } \\
\text { instructions on how to communicate to students. }\end{array}$ \\
\hline $\begin{array}{l}\text { Motivation improvements - evidence of } \\
\text { improvements in the students' motivation towards } \\
\text { their projects a result of completing the } \\
\text { instruments. }\end{array}$ & $\begin{array}{l}\text { Provide explanation about the reasoning } \\
\text { underlying the surveys ; Have peer feedbacks }\end{array}$ \\
\hline
\end{tabular}

Table 4: Feedback from focused group meeting with students

\begin{tabular}{|l|l|}
\hline Discussion Topic & Student Feedback \\
\hline $\begin{array}{l}\text { Assessment format - ways to make the } \\
\text { assessments user-friendly, preference to ask } \\
\text { students to rank-order, rate and describe issues } \\
\text { related to motivation or use a 5-point Likert scale. }\end{array}$ & $\begin{array}{l}\text { Prefer Likert-scale questions ; Use a 10 point } \\
\text { number scale instead of "Strongly agree" to } \\
\text { "Strongly disagree" which is confusing ; Reword } \\
\text { items so that they are straightforward and there is } \\
\text { consistency in the wording ; Break down } \\
\text { assessments into sections of 10 questions }\end{array}$ \\
\hline $\begin{array}{l}\text { Other assessments - the conditions under which } \\
\text { they are willing to complete more assessment } \\
\text { tools in their capstone course }\end{array}$ & $\begin{array}{l}\text { In-depth explanation of the research project / } \\
\text { reasoning behind those assessments ; } \\
\text { Opportunity to learn from the assessments }\end{array}$ \\
\hline Motivation changes - ways in which completion of & Motivation comes from the client being excited \\
\hline
\end{tabular}


these instruments have influenced their motivation towards their projects

Time investment - amount of time spent completing the instruments and the reasons underlying their willingness to invest time in these assessments about the project or being personally excited about the project

Provide incentives: Assessments as part of grade, given extra credit, payment to take all surveys; Make them easier and less time consuming; Knowing that the professor cares and is involved in the research ; Have peer feedback

Based on the feedback, we made six main changes to the instruments. They are: (a) change the Likert scale from 1-5 to 0-10, (b) change the Strongly Disagree/Strongly Agree descriptors to Rarely/Most of the time, (c) use a sliding scale to slow down students to minimize the risk of superficial engagement in the task, (d) randomly list intrinsic motivations from extrinsic ones in the attitudes instrument, and have five sections of four questions for the behaviors instrument, (e) rewrite or replace various items to prevent ambiguity and make them easier to understand, and (f) include a peer assessment section for the behaviors instrument. These changes resulted in an updated version of both instruments as shown in Table 5 and Table 6 . The instruments shown in Table 5 and Table 6 are the actual attitudes and behaviors instruments respectively. The updated version of the attitudes instrument (Table 5) still consists of 20 items with the first 10 items categorized as intrinsic and items 11-20 as extrinsic. The updated behaviors instrument (Table 6) includes a peer assessment section asking the students to rate their teammates on each of the five behavior elements, identify the element requiring most improvements, and provide suggestions for improvement.

\section{Table 5: The motivational attitudes instrument}

\begin{tabular}{|c|c|}
\hline \multicolumn{2}{|c|}{$\begin{array}{l}\text { Attitudes: How often are you motivated by the following attitudes? (The students rates } \\
\text { themselves on the following questions using a 10-point Likert scale from "Rarely" to "Most of } \\
\text { the time") }\end{array}$} \\
\hline 1. Apply professional skills & 11. Grades \\
\hline 2. Working with other people & 12. My capstone requirement for graduation \\
\hline 3. Expanding my knowledge & 13. My obligations to others \\
\hline 4. Applying technical skills & 14. A solution that satisfies sponsor needs \\
\hline 5. Managing a project & 15. A product with commercial value \\
\hline 6. Thrill of a challenge & 16. Recognition for my leadership \\
\hline 7. Satisfaction of solving open-ended problems & 17. Building a strong project portfolio \\
\hline 8. Experiencing an effective design process & 18. Getting a strong instructor reference \\
\hline 9. Passion for my work & 19. Receiving patent recognition \\
\hline 10. Gratification from benefitting others & 20. Recognition for project results \\
\hline
\end{tabular}




\section{Table 6: The motivational behaviors instrument}

Self-Behaviors: Indicate how often you exhibit the following behaviors in your capstone design project (The students rate themselves on the following questions using a 10-point Likert scale from "Rarely" to "Most of the time")

Work Quality and Quantity

1. Contribute an appropriate amount of work

2. Complete work on time

3. Produce high quality work

Focus my time on relevant tasks

\section{Level of Supervision}

1. Seek and clarify instructions

2. Adapt instructions to achieve project needs

3. Need minimum follow-up to achieve intended results

Communicate progress and results

\section{Team Effectiveness}

1. Collaborate to achieve team success

2. Contribute to a positive team climate

3. Provide and accept constructive feedback

Help teammates be successful

Initiative

1. Identify and tackle project problems

2. Respond to needs without being asked

3. Pursue needed information

Find solutions to missing team capabilities

\section{Self-Development}

1. Improve ability to solve problems

2. Develop improved interpersonal skills

3. Learn and apply technical skills

Learn and apply professional skills

Peer-Behaviors: How often do your teammates exhibit the following behaviors? (The student will rate each of their teammates on the following questions using a 10-point Likert scale from "Rarely" to "Most of the time")

1. Delivers high quality work on a schedule

2. Performs tasks by demonstrating self-reliance with appropriate supervision

3. Enhances team performance

4. Show initiative to respond to project needs

5. Develop skills and abilities to improve performance

Peer assessment \#1: For each person, click on the behavior that can benefit the most from improvement
$\circ$ Work quality and quantity
Level of supervision
Team Effectiveness
Initiative
Self-Development

Now provide a specific suggestion how to achieve desired improvement for the specified behavior.

Both versions of the instruments were administered online, via a Qualtrics survey tool. The link is made available to the students for one week, and they can complete the online questionnaire in or outside of class (a smart phone app is also available). On average, the students took ten minutes to complete each instrument. During Fall of 2017, all six capstone instructors were given the option of giving the instruments as mandatory assignments. 


\section{Analysis}

We quantitatively validated both instruments by conducting three statistical tests. Two tests, reliability index and Ferguson delta, focus on the instrument as a whole. Reliability index measures the extent to which the results are repeatable when administered under similar test conditions to the same sample of students. The desired reliability index range is $\geq 0.7$ for group measurement and $\geq 0.8$ for individual measurement. Ferguson delta measures the extent to which the entire test can differentiate between highly and poorly motivated students. The ideal range is $\geq 0.9$. The third test is item discrimination index. It focuses on individual items and measures the extent to which each item can distinguish highly motivated students from poorly motivated ones. The desired range is $\geq 0.3$. These statistical tests were performed on the data gathered during Spring and Fall of 2017. We compared the statistical outcomes from these two samples.

\section{Results}

In this section, we first highlight the validation outcomes for the initial (Table 1) and subsequently revised version (Table 5) of the motivational attitudes instrument. We then describe the results for both versions of the motivational behaviors instrument (Table 2 and Table 6).

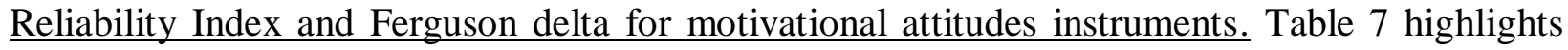
the values for the reliability index and Ferguson delta gathered from the Spring and Fall data for the initial and updated motivational attitudes instruments. For the reliability index, the results indicate that the initial version of the attitudes instrument is significantly reliable for group and individual measurements compared to the updated version where the instrument is marginally reliable for both types of measurements. For the Ferguson delta, the results indicate that regardless of the version of the attitudes instrument, the entire test can help to distinguish between highly and weakly motivated students.

Table 7: Reliability index and Ferguson delta for initial and updated attitudes instruments

\begin{tabular}{|c|c|c|}
\hline Statistical Tests & $\begin{array}{c}\text { Spring 2017 data } \\
\text { (Initial version of instrument) }\end{array}$ & $\begin{array}{c}\text { Fall 2017 data } \\
\text { (Updated version of instrument) }\end{array}$ \\
\hline Reliability index & 0.83 & 0.71 \\
\hline Ferguson delta & 0.97 & 0.98 \\
\hline
\end{tabular}

Item discrimination index for motivational attitudes instruments. The discrimination index for each item in the initial version of the attitudes instrument and the corresponding revised / replaced item in the updated instrument is shown in Table 8. Note that 5 items have been replaced i.e., items \#6, 11-13 and 16 in the initial instrument have been replaced by items\# 3, 5, 7, 8 and 18 in the updated instrument. This was done to improve discrimination. The remaining 15 statements were reworded.

For the initial version of the instrument, 7 of the 20 items have a discrimination index $\geq 0.3$ indicating that only these seven items were significantly reliable for distinguishing highly motivated students from poorly motivated ones. In contrast, for the updated instrument, a total of 14 of the 20 items have a discrimination index $\geq 0.3$. Among the 15 items which have been revised, we noted that for 11 of them, there was a positive shift in discrimination index. Most 
importantly, for six of these items, the discrimination index improved from $[0.08,0.24]$ in the initial instrument to $\geq 0.3$ in the updated instrument. For two items, there was a shift from $\leq 0.2$ to $\geq 0.2$. The three items with a discrimination index $\geq 0.3$ in the initial instrument further improved to $\geq 0.5$. For two of the revised items, there was no change in discrimination index, remaining at $\leq 0.2$. For another two revised items, there was negative shift in discrimination index, from $[0.37,0.4]$ to $[0.18,0.27]$ for the updated instrument. Among the five items which have been replaced in the updated instrument, four of them displayed a discrimination index $\geq$ 0.3. Overall, most of the items in the updated instrument have been improved with the average discrimination index changing from 0.24 to 0.32 .

Table 8: Item discrimination index for the initial and updated version of attitudes instrument ( ${ }^{*}$ indicates replaced items)

\begin{tabular}{|c|c|c|c|}
\hline \multicolumn{2}{|c|}{ Spring data (Initial version of instrument) } & \multicolumn{2}{c|}{ Fall data (Updated version of instrument) } \\
\hline Items & $\begin{array}{c}\text { Discrimination index } \\
\text { Range: [0.01, 0.45] }\end{array}$ & Items & $\begin{array}{c}\text { Discrimination index } \\
\text { Range: [0.14, 0.55] }\end{array}$ \\
\hline 1 & 0.10 & 12 & 0.23 \\
\hline 2 & 0.10 & 11 & 0.26 \\
\hline 3 & 0.21 & 1 & 0.41 \\
\hline 4 & 0.13 & 4 & 0.22 \\
\hline 5 & 0.11 & 2 & 0.29 \\
\hline 7 & 0.45 & 9 & 0.18 \\
\hline 8 & 0.16 & 13 & 0.2 \\
\hline 9 & 0.19 & 10 & 0.19 \\
\hline 10 & 0.37 & 6 & 0.27 \\
\hline 14 & 0.39 & 17 & 0.48 \\
\hline 15 & 0.08 & 20 & 0.35 \\
\hline 17 & 0.19 & 16 & 0.38 \\
\hline 18 & 0.24 & 14 & 0.27 \\
\hline 19 & 0.44 & 15 & 0.48 \\
\hline 20 & 0.45 & 19 & 0.55 \\
\hline $6^{\mp}$ & 0.40 & $3^{\mp}$ & 0.33 \\
\hline $11^{\mp}$ & 0.44 & $5^{\mp}$ & 0.28 \\
\hline $12^{\mp}$ & 0.18 & $7^{\mp}$ & 0.45 \\
\hline $13^{\mp}$ & 0.01 & $8^{\mp}$ & 0.39 \\
\hline $16^{\mp}$ & 0.16 & $18^{\mp}$ & 0.14 \\
\hline Average & $\mathbf{0 . 2 4}$ & Average & $\mathbf{0 . 3 2}$ \\
\hline
\end{tabular}

Reliability index and Ferguson delta for motivational behaviors instruments. The reliability index and Ferguson delta for the initial and updated version of the motivational behaviors instrument are shown in Table 9. For the reliability index, the results show that both versions of the instrument are reasonably reliable for group measurement. However, they are marginally reliable for individual measurement. For the Ferguson delta, the values indicate that the entire test, either initial or updated instrument, can be used to differentiate between highly and weakly motivated students. 
Table 9: Reliability index and Ferguson delta for initial and updated behaviors instrument

\begin{tabular}{|c|c|c|}
\hline Statistical Tests & $\begin{array}{c}\text { Spring 2017 data } \\
\text { (Initial version of instrument) }\end{array}$ & $\begin{array}{c}\text { Fall 2017 data } \\
\text { (Updated version of instrument) }\end{array}$ \\
\hline Reliability index & 0.73 & 0.74 \\
\hline Ferguson delta & 0.91 & 0.96 \\
\hline
\end{tabular}

Item discrimination index for motivational behaviors instruments. The discrimination indices for each item in the initial version of the behaviors instrument and in the corresponding revised/replaced item in the updated instrument are shown in Table 10. Note that two items have been replaced (i.e., items twenty and four) in the initial version instrument have been replaced by items Q2-1 and Q3-3 in the updated version in order to improve their reliability. The remaining items were reworded.

Table 10: Item discrimination index for the initial and updated version of behaviors instruments ("indicates items with reversed statements and " indicates replaced item)

\begin{tabular}{|c|c|c|c|c|}
\hline & \multicolumn{2}{|c|}{$\begin{array}{c}\text { Spring data (Initial version of } \\
\text { instrument) }\end{array}$} & \multicolumn{2}{|c|}{$\begin{array}{c}\text { Fall data (Updated version of } \\
\text { instrument) }\end{array}$} \\
\hline $\begin{array}{c}\text { Motivational } \\
\text { Behaviors elements } \\
\end{array}$ & Items & $\begin{array}{c}\text { Discrimination index } \\
\text { Range: }[-0.07,0.34]\end{array}$ & Items & $\begin{array}{c}\text { Discrimination index } \\
\text { Range: }[0.13,0.37] \\
\end{array}$ \\
\hline \multirow{4}{*}{$\begin{array}{c}\text { Work quality and } \\
\text { quantity }\end{array}$} & 1 & 0.23 & Q1-1 & 0.17 \\
\hline & $7^{\star}$ & -0.02 & Q1-2 & 0.13 \\
\hline & $8^{*}$ & 0.02 & Q1-3 & 0.13 \\
\hline & 11 & 0.19 & Q1-4 & 0.21 \\
\hline \multirow{4}{*}{ Level of Supervision } & 5 & 0.24 & Q2-2 & 0.28 \\
\hline & $16^{*}$ & 0.02 & Q2-3 & 0.37 \\
\hline & 9 & 0.26 & Q2-4 & 0.21 \\
\hline & $20^{\mp}$ & 0.31 & Q2-1 ${ }^{\mp}$ & 0.36 \\
\hline \multirow{4}{*}{ Team Effectiveness } & 14 & 0.23 & Q3-1 & 0.20 \\
\hline & $10^{*}$ & -0.03 & Q3-2 & 0.15 \\
\hline & $4^{7}$ & 0.21 & Q3-1 ${ }^{\mp}$ & 0.18 \\
\hline & 19 & 0.34 & Q3-4 & 0.14 \\
\hline \multirow{4}{*}{ Initiative } & $2^{*}$ & 0 & Q4-1 & 0.18 \\
\hline & 12 & 0.26 & Q4-2 & 0.17 \\
\hline & $13^{*}$ & -0.02 & Q4-3 & 0.1 \\
\hline & 18 & 0.31 & Q4-4 & 0.29 \\
\hline \multirow{5}{*}{ Self-development } & $3^{*}$ & 0.02 & Q5-1 & 0.21 \\
\hline & 6 & 0.23 & Q5-2 & 0.28 \\
\hline & 15 & 0.15 & Q5-3 & 0.17 \\
\hline & $17^{*}$ & -0.07 & Q5-4 & 0.23 \\
\hline & Average & 0.14 & Average & 0.21 \\
\hline
\end{tabular}

For the initial version of the instrument, only five of the twenty items were significantly reliable for distinguishing between highly and weakly motivated students i.e., they have a discrimination index $\geq 0.3$. Similarly, for the updated version, five of the twenty items have a discrimination index $\geq 0.3$. Among the 18 items which have been revised, we noted a positive shift in discrimination index for 10 items: from $[-0.07,0.02]$ to $[0.13,0.37]$ for eight items, and from $\geq$ 0.2 to $\geq 0.3$ for two items. For four items, there was no change in discrimination index, remaining either at $\leq 0.2$ or $\geq 0.3$. For another four items, we noted a negative shift in discrimination index, from $\geq 0.2$ and $\geq 0.3$ for the initial version to $\leq 0.2$ for the updated 
instrument. For the two items which were replaced, only one of them allows us to significantly distinguish between highly and weakly motivated students i.e., discrimination index $\geq 0.3$. For the initial version of the instrument, a total of eight items were written in reverse context and/or led to possible dual meanings resulting in a very low discrimination index [-0.07, 0.02].

The discrimination index of one of the items is zero and a negative number for the other four items. A zero discrimination index indicates that the item cannot be used to distinguish between highly and poorly motivated students. The particular item (question two: It was challenging to initiate actions to start and complete work assigned to me) was interpreted and evaluated by students of different motivation levels in a similar way. In other words, there is no difference in the response of the weakly and highly motivated students. They may have chosen the same option as their answer. A negative discrimination index shows that the statement was interpreted and assessed in an opposite manner by highly and poorly motivated students. For example, question seven (I have needed extra time to complete my project work assignments) was intended to be a reverse item. However, it can be treated as a positive statement by highly motivated students (i.e. since one is highly motivated, one needs extra time to produce high quality work (rather than one being highly motivated such that no extra time is needed to complete an assignment). As such, a highly motivated student may "agree/strongly agree" with the statement. In contrast, weakly motivated students may have treated this item as a negative statement such that they "disagree/strongly disagree" with it. Based on the outcomes for the initial version of the instrument, we have additionally rephrased those eight items to be positive statements.

Overall, most of the items in the updated behaviors instrument have been moderately improved with the average discrimination index changing from 0.14 to 0.21 .

\section{Conclusion and Discussion}

The three statistical tests indicate that the updated motivational attitudes instrument is less reliable compared to the initial version despite having more items with reasonably good discriminatory ability to distinguish between highly and poorly motivated students. Further, there is no major difference in the reliability of the initial and updated motivational behaviors instrument. Both versions are moderately reliable for group measurement and poorly reliable for individual measurement with items of marginal discriminatory ability. These outcomes can be explained by the differences in the structure of the initial and updated versions of the instruments. Five main structural changes were implemented in both the attitudes and behaviors instruments as highlighted in the method section.

Based on these findings, we have further refined the attitudes assessments and will apply for the second time in the second semester. We revisited each statement and reworded where necessary to make them more relevant to the capstone context to reduce misinterpretation. Some of the statements in the updated attitudes instrument administered during the Fall of 2017 were too open-ended and therefore not particularly specific to the capstone course and project. We also reordered the items in random fashion relative to intrinsic and extrinsic attitudes. Finally, we reverted to the original five-point Likert scale and the descriptors "Strongly agree" and "Strongly disagree". Similar revisions to the behaviors instrument are in progress. The next step is to 
administer the refined instruments to the same group of students during Spring of 2018 and quantitatively validate the assessment tools.

Successful development of these assessment instruments to measure student motivation provides an important tool in curriculum development. There exist many forms of capstone design curricula, ranging from single-person projects to multidisciplinary teams and from artificial problem statements and design competitions to real-world problems directed by industry sponsors. While curricula can be difficult to change, faculty and administration have the opportunity to modify capstone courses to help students better achieve one of industry's most highly sought outcomes--personal motivation. As a result of this research, we are closer to measuring the levels of student motivation in capstone courses. Using the fundamental theses of Ryan and Deci [9], faculty can improve students' migration toward intrinsic motivation and increased learning efficiency by applying the three foundations of self development theory. By increasing the level of autonomy (allowing students to pick their own project or working on open-ended projects), relatedness (working on teams, interfacing with faculty and clients, and working on projects with personal significance), and competence (learning the basic elements of product/process design, applying elements of entrepreneurial minded learning, and creating business models using the business model canvas), we should improve students' motivation. The results of this research can verify the impacts of curricular change on motivation. Future research to validate the effects of curricular change on student motivation in capstone courses can be accomplished by modifying an existing capstone course to increase students' autonomy, relatedness, and competency. Migrate an existing course toward applying multidisciplinary teams--including engineering, business, and design students. Encourage teams to work with a client and identify an opportunity whose solution has significant and measureable social and/or economic value. Provide teams with effective faculty and industry mentors acting as coaches, focus on creating and enhancing effective teamwork, teach a rigorous product/process development process, and require parallel technical and business approaches to solutions. Applying the instruments developed in this research, faculty can evaluate the influence of this curricular change on students' motivation by using pre- and post-assessments of both the existing and modified course.

\section{Acknowledgements}

The project team would like to thank the National Science Foundation for support of this work through grant number DUE 1504728.

\section{References}

1. National Academy of Sciences, National Academy of Engineering, and Institute of Medicine, Rising Above the Gathering Storm: Energizing and Employing America for a Brighter Economic Future, Washington, DC, The National Academies Press, 2007. Retrieved from: https://s3.wp.wsu.edu/uploads/sites/618/2015/11/Rising-Above-theGathering-Storm.pdf

2. American Society for Engineering education, "Phase I: Synthesizing and Integrating Industry Perspectives," Transforming Undergraduate Education in Engineering (TUEE), Arlington, VA, May 9-10, 2014. 
3. American Society for Engineering education, "Phase II: Insights from Tomorrow's Engineers," Transforming Undergraduate Education in Engineering (TUEE), Washington DC, December 2017.

4. G. Wiggins and J. McTighe, "What is Backward Design?," in Understanding by Design, Alexandria, VA: Association for Supervision and Curriculum Development, 1998.

5. National Research Council, Knowing What Students Know: The Science and Design of Educational Assessment, Washington, DC, The National Academies Press, 2001.

6. R. J. Stiggins, Student-Centered Classroom Assessment. Merrill Pub Co: $2^{\text {nd }}$ Edition, 1996.

7. Goodman Research Group. "Motivated Strategies for Learning Questionnaire (MSLQ)." Waltham, MA: Education Development Center, n.d.http://stelar.edc.org/instruments/motivated-strategies-learningquestionnaire-mslq

8. M. McCormick, A. Bielefeldt, C. Swan, and K. Paterson, "Assessing Students' Motivation to Engage in Sustainable Engineering." International Journal of Sustainability in Higher Education 16, no. 2 (2015): 136-54.

9. E. Deci and R. Richard, "Self-Regulation and the Problem of Human Autonomy: Does Psychology Need Choice, Self-Determination, and Will?", Journal of Personality and Social Psychology, 74(6), pp 1557-85, 2006.

10. R. L. Kajfez and H. M. Matusovich, "Competence, Autonomy, and Relatedness as Motivators of Graduate Teaching Assistants," The Research Journal for Engineering Education, 106, pp 245-272, 2017.

11. P. Rogers, D. C. Davis, S. Winfree, K. Ash, B. Ibrahim and L. Ding. Early Validation of the Motivation in Team Projects (MTP) Assessment. In Proceedings American Society for Engineering Education Annual Conference. Columbus, OH, 2017. 